\title{
Production of Similar Fragments from the Glycine, Alanine, and Methionine Amino Acid Molecules under Low-Energy Electron Impact
}

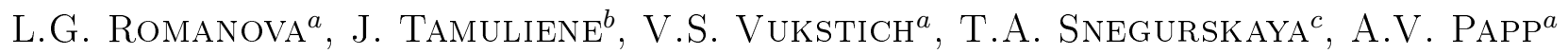 \\ AND A.V. SNEGURSKY ${ }^{a, *}$ \\ ${ }^{a}$ Institute of Electron Physics, Ukrainian National Academy of Sciences, \\ 21 Universitetska str., 88017 Uzhgorod, Ukraine \\ ${ }^{b}$ Vilnius University, Institute of Theoretical Physics and Astronomy, 12 A. Goštauto str., 01108, Vilnius, Lithuania \\ ${ }^{c}$ Uzhgorod National University, Department of Physics, 46 Pidhirna str., 88000 Uzhgorod, Ukraine
}

(Received March 30, 2015; in final form April 24, 2015)

\begin{abstract}
Production of the ionic fragments of the same chemical composition due to a low-energy electron impact on the glycine, alanine, and methionine amino acid molecules has been studied both experimentally and theoretically. The mass-spectrometric technique was applied to detect the above ionic fragments within the 1-720 a.m.u. mass range with the \pm 0.25 a.m.u. resolution, while the density functional theory based theoretical approach allowed the relevant species to be identified and the mechanisms of their production to be clarified. A special attention has been paid to analysis of the geometrical structures of the molecules under study as well to finding the appearance potentials of their fragments with the accuracy of $\pm 0.1 \mathrm{eV}$.
\end{abstract}

DOI: $10.12693 /$ APhysPolA.128.15

PACS: 34.50.Lf, 34.90. $+\mathrm{q}$

\section{Introduction}

Amino acids being biologically relevant organic substances involved in the live organisms include generally the amine $\left(\mathrm{NH}_{2}\right)$ and the carboxylic acid $(\mathrm{COOH})$ functional groups. Their generic formula looks like $\mathrm{H}_{2} \mathrm{NCHRCOOH}$ (R being an organic substituent, the socalled "side-chain" [1]). Amino acids also serve as building blocks of proteins and intermediates in metabolism. The chemical properties of these molecules determine the biological activity of the proteins. In addition, proteins contain the necessary information needed to determine the structure and the stability of the live organism. This is an important field of scientific research, and today it is still one of the most important tasks of modern biological and chemical science [2].

Regarding the possible degradation of amino acids under the external impact, it is a well-known fact that ionizing radiation causes in live tissue the irreversible effects at the genetic level [3]. The mechanism of such degradation does not include the direct action of high-energy ionizing radiation only, because the influence of the processes related to the low-energy secondary electrons appears to be significant [4]. Secondary products of ionizing radiation in living tissues are capable of damaging the structural units of nucleic acids and proteins leading, in particular, to dissociative ionization with both positive and negative-ion production. Thus, the low-energy

*corresponding author; e-mail: snegursky.alex@gmail.com electrons are of a primary interest from the viewpoint of tracing the consequences of malignant transformations in living cells under the influence of ionizing radiation and also provide useful radiation therapy effect on tumors in human beings [5].

The studies of the basic mechanisms of the amino acid molecule structural changes caused by low-energy electron impact are far from being complete despite their undoubted significance. According to the National Institute of Standards (NIST) database [6], the available relevant data are a bit disputable, while those on the parent molecule ionization thresholds and fragment appearance energies are extremely scarce.<smiles>CSCCC(N)C(=O)O</smiles>

Fig. 1. Structural formulae of the molecules under study.

In our previous papers (see, e.g. [7-9]), we have studied both experimentally and theoretically fragmentation of the glycine, alanine, and methionine molecules by low-energy (below $150 \mathrm{eV}$ ) electrons and noticed yield of some fragments of the above three molecules having the same chemical composition not comparing their production mechanisms. Therefore, the aim of the present paper was to study the mechanisms of their production and compare these mechanisms with each other. The amino acid glycine, alanine, and methionine 
molecules (see schematic view in Fig. 1) have different substituents $\mathrm{R}$ : $-\mathrm{H},-\mathrm{CH}_{3}$ and $-\mathrm{C}_{2} \mathrm{H}_{4} \mathrm{SCH}_{3}$. One of them (methionine) involves not only the main constituents such as carbon and hydrogen, but also the sulfur atom. The above molecules present good example for predicting the influence of substituents on the process of fragmentation of the core part $\left(\mathrm{H}_{2} \mathrm{NCHCOOH}\right)$ of the amino acid. To our knowledge, no similar data are present in literature.

\section{Experimental}

In our study, we used a conventional magnetic massspectrometer MI-1201 (see, e.g. [10]) as the massseparator unit enabling the fragments of electronmolecule interaction to be identified. Figure 2 shows the schematic diagram of the experimental setup. The experimental apparatus developed and applied is based, as already mentioned above, on the magnetic mass spectrometer capable of operating within the 1-720 a.m.u. mass range. High sensitivity $\left(\approx 10^{-16} \mathrm{~A}\right)$ and resolution $( \pm 0.25$ a.m.u.) of the mass analyzer enabled the fragments of the target molecule to be reliably separated and detected even at low levels of ion currents reaching the ion detector (see Fig. 2).

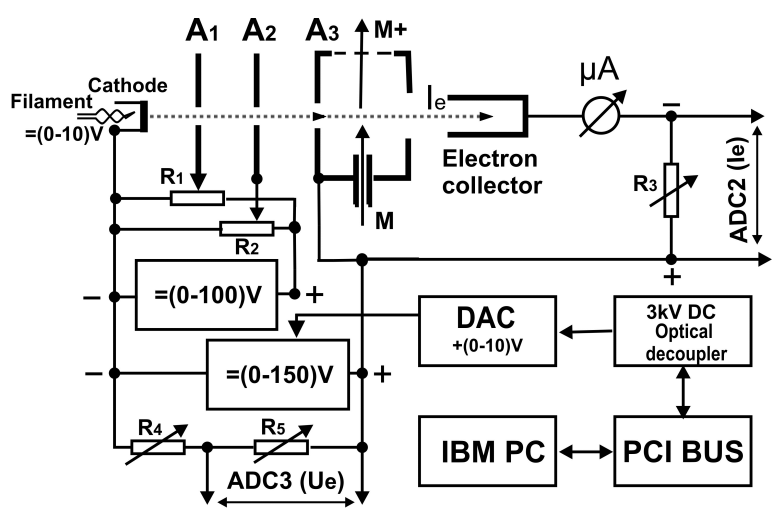

Fig. 2. Schematic diagram of the experimental setup and supporting electrical circuits.

The primary molecular beam ( $M$ in Fig. 2) was formed by means of an effusion source with a resistive oven providing target molecule concentrations not less than $10^{10}$ molecule $/ \mathrm{cm}^{3}$. The operating temperature of the molecular beam source was varied up to $200^{\circ} \mathrm{C}$ being controlled by a thermocouple allowing the temperature dependences of the fragment yields to be determined. As it has been shown in our previous papers [7-9], the linear behaviour of the above temperature dependences (plotted in the semi-logarithmic scale) within the temperature range of $50-120^{\circ} \mathrm{C}$ indicated unambiguously that production of the above fragments due to the thermal degradation of the parent molecule was negligible.

The temperature and pressure conditions of the molecular beam formation excluded the possibility of molecular cluster formation. A specially designed three-electrode electron gun provided an electron current $I_{e}=30-50 \mu \mathrm{A}$ within a wide $(0-150 \mathrm{eV})$ energy range with the energy spread $<0.3 \mathrm{eV}$ (full width at the half-maximum of the beam energy distribution) [10]. The experimental appearance potentials were determined by means of a fitting technique based on the least-squares method approximation using the Marquardt-Levenberg algorithm described in detail in our previous studies (see. e.g. [7-10]). The accuracy of the appearance potential determination was not worse than $\pm 0.1 \mathrm{eV}$. The energy dependences of ionization and dissociative ionization cross-sections to be measured in the incident electron energy range from the threshold up to $150 \mathrm{eV}$. The ions produced in the ion source and extracted by the electric field entered a magnetic ion separator and were detected by means of an electrometer.

The data acquisition and processing system was controlled by a PC. Special measures were taken to stabilize the mass analyzer transmission, thus, making the mass of the fragment under study to be reliably fixed. An electron energy scale was calibrated with respect to known ionization thresholds for argon atom and nitrogen molecule (see below) with the accuracy not worse than $\pm 0.1 \mathrm{eV}$. The molecular beam $M$ (see Fig. 2) was directed to the ionization chamber normally to the electron beam (the beams intersect in the figure plane). The experimental procedure was as follows.

First both electron and molecular beam sources were put into operation and after reaching the optimal conditions of beam generation a mass spectrum of the molecules under study was measured. The masses of the fragments produced were then fixed and the energy dependences of the relevant ion yields were measured. Electron energy was varied with an energy step of $0.1-0.3 \mathrm{eV}$ enabling the threshold areas of the dissociative ionization functions for all the fragments under study to be measured. In this case the problem of the incident electron energy scale calibration becomes very significant. To calibrate the above energy scale we have measured the threshold areas of the ionization functions for the two test gases $-\mathrm{Ar}$ and $\mathrm{N}_{2}$. The experimental ionization thresholds were determined by means of a fitting technique is based on a least-squares method approximation using the Marquardt-Levenberg algorithm suggested by Maerk's group (see, e.g., our earlier paper [11]).

\section{Theoretical}

The structures of the molecules and their fragments were studied using the generalized gradient approximation for the exchange-correlation potential in the density functional theory (DFT) as it is described by the Becke three-parameter hybrid functional, applying the non-local correlation provided by Lee, Yang, and Parr. The DFT method is commonly referred to as B3LYP [12], i.e. as a representative standard one described in more detail below. The cc-pVTZ basis set was used as well [13]. The structures of the molecule isomers/conformers and their fragments under study were optimized globally 
without any symmetry constraint. The bond order and the bond length of the molecule conformers were investigated to find the weaker bonds possible to be destructed. Additionally, the vibration spectrum was evaluated to predict the possible elongation of bonds and the change of the angle aiming to analyze the most probable fragments produced due to electron impact. On the other hand, the results on the vibration modes were analyzed to be sure that the equilibrium point of the molecular systems was found. In order to model the fragmentation processes, the possible fragment anions, cations and fragments with a zero charge were evaluated. Dissociation energies were calculated as the difference between the total energy of the molecule and the sum of the energies of the fragments predicted. We assumed that in our experimental conditions the structure of the fragments formed could be changed influencing, thus, the dissociation energy. To evaluate the above influence, the dissociation energy was calculated for the following two cases: (i) the single point energy calculation of the fragments was performed taking into account the geometry of a certain part of the molecules under study (in these cases the energy of fragment formation is not the lowest one); (ii) the structure of the fragments was optimized, i.e. the fragments were allowed to reach their equilibrium geometry and the obtained energy (the lowest energy of the fragments) was used to calculate the dissociation energy.

\section{Results and discussion}

The amino acid molecules studied by us, despite their different composition, produce a series of neutral and ionic fragments with the same mass. Therefore, comparison of possible mechanisms of their production is of certain interest when studying the processes of the initial molecule decomposition. Obviously, it is intriguing to trace their production in this process as well as to study the possible mechanisms of their formation. In this section, we will summarize some results of our studies.

Figure 3 shows the mass spectra of the three molecules under study measured using the technique described above. We would like to draw attention that the glycine, alanine, and methionine molecules could be presented as the $\mathrm{COOH}-\mathrm{CHR}-\mathrm{NH}_{2}$ compounds, where $\mathrm{R}$ is $-\mathrm{H},-\mathrm{CH}_{3}$ and $\mathrm{C}_{2} \mathrm{H}_{4}-\mathrm{S}-\mathrm{CH}_{3}$ in case of glycine, alanine, and methionine, respectively. This allows one to expect that several fragments with equal mass could be formed under the low-energy electron impact. Formally, such fragments could be $\mathrm{NH}_{2}$ ( $m=16$ a.m.u. $), \mathrm{CH}_{2} \mathrm{~N}, \mathrm{CO}(m=$ 28 a.m.u.), $\mathrm{CH}_{3} \mathrm{~N}, \mathrm{COH}(m=29$ a.m.u. $), \mathrm{CH}_{4} \mathrm{~N}, \mathrm{CH}_{2} \mathrm{O}$ ( $m=30$ a.m.u.), $\mathrm{C}_{2} \mathrm{H}_{4} \mathrm{~N}$ ( $m=42$ a.m.u.), $\mathrm{CO}_{2}, \mathrm{C}_{2} \mathrm{H}_{6} \mathrm{~N}$ ( $m=44$ a.m.u.), $\mathrm{CHO}_{2}(m=45$ a.m.u. $)$ and $\mathrm{C}_{2} \mathrm{HO}_{2}$, $\mathrm{C}_{2} \mathrm{H}_{3} \mathrm{NO}$ ( $m=57$ a.m.u.) and they may be charged both positively and negatively or be neutral. It should be emphasized that we have no possibility to measure the mass spectra of negatively charged ions as well as the appearance energies for such fragments, thus, some of the results presented below are based on the theoretical considerations only.
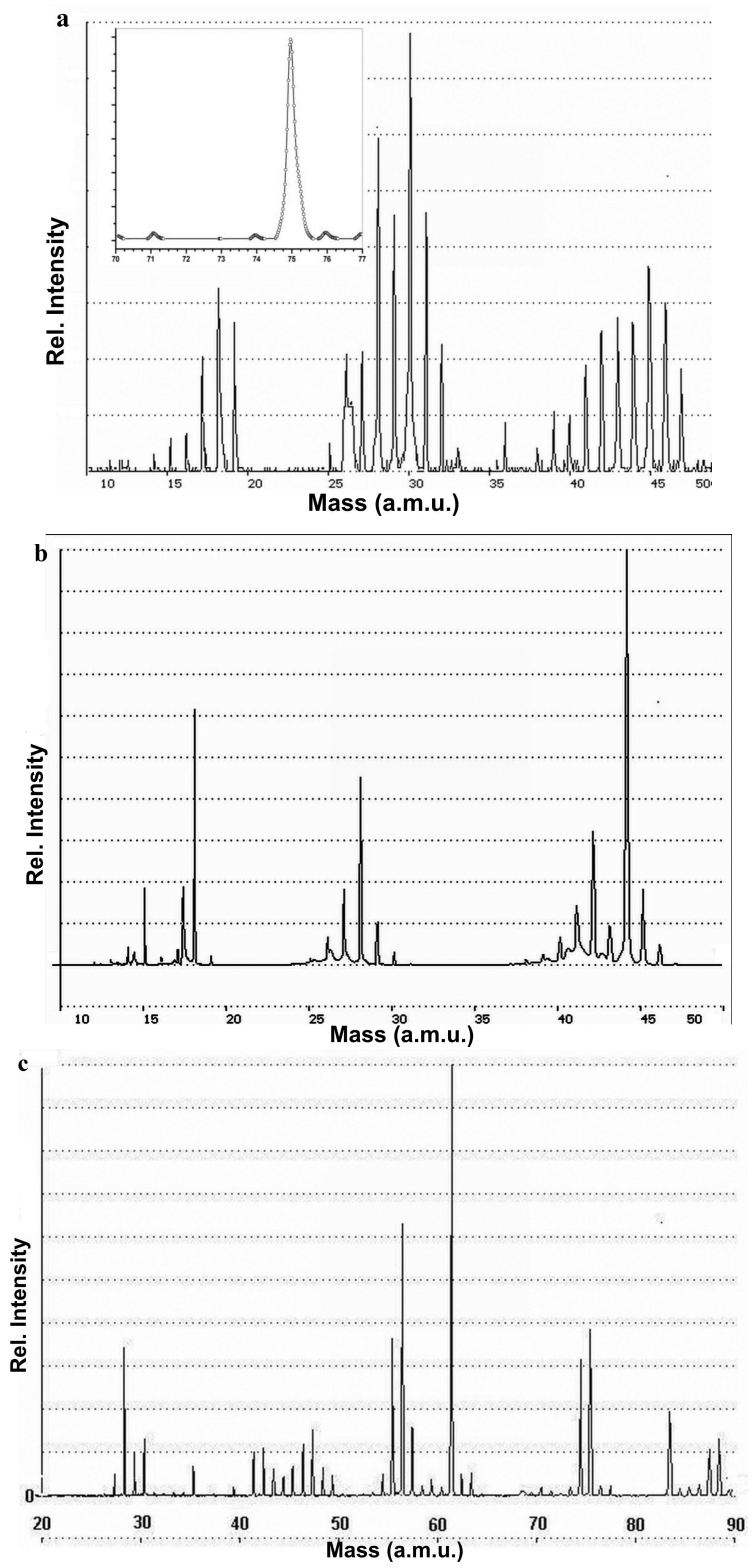

Fig. 3. Initial areas of the mass spectra of the molecules under study: (a) glycine molecule, inset that in the vicinity of the parent molecule peak, (b) $\alpha$ alanine molecule, (c) methionine molecule.

\subsection{Detachment of amino acid molecules functional groups}

\subsubsection{Deamination}

The mass spectra of the above amino acids reveal a small-scale peak of the $\mathrm{NH}_{2}^{+}(m=16$ a.m.u.) fragment, because the peaks observed are due to fragmentation of the molecule by a preferred cleavage of those bonds, which lead to energetically more favored, i.e. best stabilized, ions. Indeed, $\mathrm{NH}_{2}^{+}$stability is very low as compared to that of the neutral and negatively charged ones (see Table I).

The positively charged amino group detachment from the parent molecule is the rare event, despite the rela- 
TABLE I

Binding energy per atom $(\mathrm{eV})$ for the differently charged fragments produced from the above molecules.

\begin{tabular}{c|c|c|c}
\hline \hline \multirow{2}{*}{ Fragment } & \multicolumn{3}{|c}{ Fragment charge } \\
\cline { 2 - 4 } & -1 & 0 & 1 \\
\hline $\mathrm{NH}_{2}$ & 3.43 & 3.38 & 0.83 \\
$\mathrm{COOH}$ & 4.13 & 4.45 & 1.31 \\
$\mathrm{CH}_{4} \mathrm{~N}$ & 3.94 & 4.12 & 3.06 \\
$\mathrm{CH}_{3} \mathrm{~N}$ & 3.94 & 4.24 & 2.63 \\
$\mathrm{CH}_{2} \mathrm{~N}$ & 4.10 & 4.39 & 2.27 \\
$\mathrm{CHO}$ & 4.02 & 3.63 & 0.93 \\
$\mathrm{CH}_{6} \mathrm{~N}$ & 4.20 & 4.32 & 3.71 \\
$\mathrm{C}_{4} \mathrm{H}_{10} \mathrm{NS}$ & 4.24 & 4.28 & 3.94 \\
$\mathrm{C}_{2} \mathrm{H}_{4} \mathrm{NO}$ & 4.71 & 4.63 & 3.82 \\
$\mathrm{C}_{2} \mathrm{HO}_{2}$ & 4.78 & 4.34 & 2.14 \\
$\mathrm{C}_{2} \mathrm{H}_{3} \mathrm{NO}$ & 4.53 & 4.73 & 3.60
\end{tabular}

tively low values of calculated energies required to break the $\mathrm{C}-\mathrm{N}$ bond but our theoretical investigations predict that, under a low-energy electron impact, all the molecules investigated could produce the $m=16$ a.m.u. mass fragment assigned as $\mathrm{NH}_{2}^{-}$. In addition, the amine fragment could be obtained as the other product when it has negative or zero charge. In the case of glycine the $\mathrm{NH}_{2}^{-/ 0 /+}$ fragment could be formed with very low possibility in the appearance energy range 12.85-25.58 eV [7] (the other fragment formed is positively charged). For the alanine molecule this calculated energy is equal to 12.04-24.77 eV depending on the structural differences between the isomers and intramolecular hydrogen bonding [8], and for the methionine molecule, the $\mathrm{NH}_{2}^{-/ 0 /+}$ fragment can be formed as well at $10.42-23.14 \mathrm{eV}$ [9].

\subsubsection{Carboxyl group detachment}

According to the early (that has become classical) work [14], fragmentation of amino acid molecules is related to the removal of one electron from the nitrogen lone pair resulting in the charge localization on the nitrogen atom and on the adjacent $\alpha$-carbon atom. Such "amine type" ionization seems to dominate over the other possible ionization channels with the nitrogen atom producing the iminium ion structure typical in the dissociative ionization of amines

$$
\mathrm{HOOC}-\mathrm{CHR}-\mathrm{NH}_{2} \stackrel{e}{\rightarrow} \mathrm{HOOC}-\stackrel{\mathrm{CHR}}{-}-\mathrm{NH}_{2}^{+} \rightarrow \mathrm{COOH}+\mathrm{CHR}=\stackrel{+}{\mathrm{N}} \mathrm{H}_{2} \text {. }
$$

Here $\mathrm{R}$ is an amino acid side chain. The one-electron shift $(\curvearrowright)$ from both the ionized nitrogen atom and the $\alpha$-carbon atom results in the double bond formation accompanied by the energy release.

This $\mathrm{C}-\mathrm{C}_{\alpha}$ bond rupture and the carboxyl group detachment is a dominant channel of the glycine and alanine molecule fragmentation. But in case of methionine this process is much less efficient as compared to the dissociation channel occurring via the $\mathrm{C}_{\beta}-\mathrm{C}_{\gamma}$ bond rupture that is, evidently, due to the influence of the sulfur atom that changes the HOMO character. So the side chain of amino acids affects considerably the dissociative process (1). While the hydrogen atom ( $\mathrm{R}$ in the glycine molecule) substitution by the methyl group does not influence the character of the main fragmentation channel, the presence of the sulfur atom complicates significantly this process.

In case of glycine after the $\mathrm{C}-\mathrm{C}_{\alpha}$ bond rupture two complementary fragments $\mathrm{CHO}_{2}(m=45$ a.m.u.) and $\mathrm{CH}_{4} \mathrm{~N}$ ( $m=30$ a.m.u.) appear. The calculated binding energy per atom shows that $\mathrm{CH}_{4} \mathrm{~N}^{+}$is three times more stable than $\mathrm{COOH}^{+}$(see Table I). Hence, formation of $\mathrm{CH}_{4} \mathrm{~N}^{+}(m=30$ a.m.u. $)$ and $\mathrm{COOH}^{-}(m=$ 45 a.m.u.) is more probable because of the energetically more favored ion formation, and this leads to the small (nearly $3 \%$ relative intensity) peak at $m=45$ a.m.u. in the glycine mass spectrum.

In the mass-spectra of the alanine and methionine molecules, the fragment with the $m=45$ a.m.u. mass assigned to $\mathrm{COOH}$ could be observed as well with the intensities $\approx 3 \%$ and $\approx 14 \%$, respectively. In case of the alanine molecule, the theoretical results prove that reaction

$$
\mathrm{C}_{3} \mathrm{H}_{7} \mathrm{NO}_{2}+\mathrm{e} \rightarrow \mathrm{C}_{2} \mathrm{H}_{6} \mathrm{~N}^{+}+\mathrm{CHO}_{2}^{-}+\mathrm{e}
$$

could be more probable due to the stability of the fragments produced, however, the comparison of the calculated and measured appearance energies indicates that reaction

$$
\mathrm{C}_{3} \mathrm{H}_{7} \mathrm{NO}_{2}+\mathrm{e} \rightarrow \mathrm{C}_{2} \mathrm{H}_{6} \mathrm{~N}^{+}+\mathrm{CHO}_{2}+2 \mathrm{e}
$$

is more energetically probable, i.e. $\mathrm{C}_{2} \mathrm{H}_{6} \mathrm{~N}^{+}$and $\mathrm{CHO}_{2}^{0}$ formation is more expected, while $\mathrm{CHO}_{2}^{+}$could be formed only in the case when the hydrogen bond $\mathrm{O} \cdots \mathrm{H}$ in the alanine molecule occur favoring this fragment stability.

It is interesting that in case of methionine the fragment with the $m=45$ a.m.u. mass is produced with higher intensity as compared with other amino acids under study. This peak increase may be due to the isobaric fragments, such as $\mathrm{CHS}^{+}$and $\mathrm{C}_{2} \mathrm{H}_{7} \mathrm{~N}^{+}$that can contribute to the peak intensity. We assign the peak at $m=45$ a.m.u. to the $\mathrm{COOH}^{+}$fragment because in order to produce the above fragment the rupture of only one $\mathrm{C}-\mathrm{C}$ bond is required, while formation of other isobaric fragments, such as $\mathrm{CHS}^{+}$and $\mathrm{C}_{2} \mathrm{H}_{7} \mathrm{~N}^{+}$, require a break of several bonds and, in some cases, the rearrangement of the hydrogen atoms. In addition, our experimental appearance energy values obtained for the fragments with $m=45$ a.m.u. $(13.5 \pm 0.1 \mathrm{eV})$ and $m=104$ a.m.u. $(9.7 \pm 0.1 \mathrm{eV})$ are close to the calculated ones. According to our data, the intensity of the peak at $m=45$ a.m.u. is somewhat lower than that of the complementary peak at $m=104$ a.m.u., thus, after the $\mathrm{C}-\mathrm{C}_{\alpha}$ bond rupture the cation center is mainly displaced to the $\mathrm{C}_{4} \mathrm{H}_{10} \mathrm{NS}$ fragment. The calculated appearance energies for $\mathrm{CHO}_{2}$ and for the complementary fragments of the glycine, alanine, and methionine molecules are presented in Table II.

The last row of this table shows the energy of the $\mathrm{C}-\mathrm{C}_{\alpha}$ bond rupture calculated not taking into account the ionization energies and electron affinities of the complementary fragments produced. Certainly, the $\mathrm{C}-\mathrm{C}_{\alpha}$ bond 
TABLE II

Calculated appearance energies (in eV) for the $\mathrm{CHO}_{2}$ and complementary fragments for glycine, alanine, and methionine molecules.

\begin{tabular}{c|c|c|c|c}
\hline \hline \multirow{2}{*}{$\begin{array}{c}\mathrm{CHO}_{2} \\
\text { (25 a.m.u. })\end{array}$} & \multirow{2}{*}{$\begin{array}{c}\text { Complementary } \\
\text { fragment charge }\end{array}$} & \multicolumn{3}{|c|}{ Appearance energy } \\
\cline { 3 - 5 } & & & & \\
\hline 1 & 1 & 8.57 & 7.58 & 7.35 \\
0 & 1 & 9.99 & 9.12 & 8.7 \\
1 & -1 & 16.11 & 13.16 & 12.34 \\
1 & 0 & 14.99 & 12.08 & 11.76 \\
0 & 0 & - & 3.51 & 3.14
\end{tabular}

dissociation energy and the appearance energy for the above ions depend on the "side-chain" type in the amino acid molecule and decrease with its increase.

Summarizing the results discussed above related to the functional group detachment, one may predict that the $\mathrm{NH}_{2}^{-/ 0 /+}$ and $\mathrm{COOH}^{-/ 0 /+}$ fragments are formed when the glycine, alanine, or methionine molecules undergo the low-energy electron impact. The comparison of the calculated appearance energies for these fragments of three amino acids shows that the decrease of the complementary fragment mass reduces the calculated appearance energy for these fragments.

\subsection{Production of the ionic fragments of the same chemical composition}

4.2.1. Fragments with the $m=28$, 29 and 30 a.m.u. masses

The fragment peak with $m=30$ a.m.u. in the glycine, alanine, and methionine mass spectra is accompanied by the satellite peaks with the $m=28$ and $m=29$ a.m.u. masses. When analyzing the appearance of the fragments with the masses $m=28$ and 29 a.m.u., we would like to draw a special attention to the formation of the fragment with the $m=30$ a.m.u. mass due to the assumption that the fragments with the $m=28$ and 29 a.m.u. masses may be related to this one.

The fragment with the $m=30$ a.m.u. mass (i.e. the $\mathrm{CH}_{4} \mathrm{~N}^{+}$ion) is the most prominent peak in the glycine mass-spectrum (Fig. 3a). According to our results reported in [15], the appearance energy for the $\mathrm{CH}_{4} \mathrm{~N}^{+}$ fragment of the glycine molecule is $10.1 \pm 0.1 \mathrm{eV}$ being close to the calculated value and this fragment is produced via the following pathway:

$$
\mathrm{C}_{2} \mathrm{H}_{5} \mathrm{NO}_{2}+\mathrm{e} \rightarrow \mathrm{CHO}_{2}^{0}+\mathrm{CH}_{4} \mathrm{~N}^{+}+2 \mathrm{e},
$$

i.e. the fragment is formed due to a simple rupture of the $\mathrm{C}-\mathrm{C}_{\alpha}$ bond and the carboxyl group detachment according to pathway (1).

Formation of the fragment with $m=30$ a.m.u. at the dissociative ionization of the alanine and methionine molecules requires additional energy consumption for the carboxyl group detachment and one more skeleton bond rupture with simultaneous hydrogen atom displacement. Of the molecules under study, the $\mathrm{H}$-atom migration process is most complicated in alanine, and due to this fact the $\mathrm{CH}_{4} \mathrm{~N}^{+}$ion peak intensity in its mass-spectrum is very small and lower than those of the $\mathrm{CH}_{3} \mathrm{~N}^{+}$and $\mathrm{CH}_{2} \mathrm{~N}^{+}$ion peaks, production of which requires less number of regrouping.

However, in case of the methionine molecule, formation of the $\mathrm{CH}_{4} \mathrm{~N}^{+}$ion can proceed due to the rearrangement of one hydrogen atom upon fragmentation from different parts of the molecule. The fragment with $m=30$ a.m.u. could be produced differently via the following pathways:

$$
\begin{aligned}
& \mathrm{C}_{5} \mathrm{H}_{11} \mathrm{NO}_{2} \mathrm{~S}+\mathrm{e} \rightarrow \\
& \left\{\begin{array}{l}
\left(\mathrm{CH}_{3} \mathrm{~N}+\mathrm{H}\right)^{+}+\left(\mathrm{COOH}+\mathrm{C}_{3} \mathrm{H}_{6} \mathrm{~S}\right)^{-}+\mathrm{e}, \\
\left(\mathrm{CH}_{3} \mathrm{~N}+\mathrm{H}\right)^{+}+\left(\mathrm{COO}+\mathrm{C}_{3} \mathrm{H}_{7} \mathrm{~S}\right)^{-}+\mathrm{e} \\
\left(\mathrm{CH}_{3} \mathrm{~N}+\mathrm{H}\right)^{+}+\left(\mathrm{COO}+\mathrm{C}_{3} \mathrm{H}_{7} \mathrm{~S}\right)^{0}+2 \mathrm{e} \\
\left(\mathrm{CH}_{3} \mathrm{~N}+\mathrm{H}\right)^{+}+\left(\mathrm{COOH}+\mathrm{C}_{3} \mathrm{H}_{6} \mathrm{~S}\right)^{0}+2 \mathrm{e} .
\end{array}\right.
\end{aligned}
$$

In the above cases the $\left(\mathrm{CH}_{3} \mathrm{~N}+\mathrm{H}\right)$ compound becomes the most stable when the $\mathrm{H}$ atom is joined with $\mathrm{CH}_{3} \mathrm{~N}^{+}$, i.e. when the lowest-energy geometry is reached and the $\mathrm{CH}_{4} \mathrm{~N}^{+}$fragment is formed. The hydrogen atom attachment to $\mathrm{CH}_{3} \mathrm{~N}^{+}$is followed by release of the 6.12 or $7.85 \mathrm{eV}$ energy, when $\mathrm{H}$ originates from the $\mathrm{C}_{3} \mathrm{H}_{7} \mathrm{~S}$ or $\mathrm{COOH}$ fragment, respectively. Thus, the hydrogen atom from the hydroxyl group preferably takes part in the $\mathrm{CH}_{4} \mathrm{~N}^{+}$fragment formation. In this case, the lowest energy is required to divide the methionine molecule into the $\left(\mathrm{COO}+\mathrm{C}_{3} \mathrm{H}_{7} \mathrm{~S}\right)^{-}$anion and the $\mathrm{CH}_{4} \mathrm{~N}^{+}$cation.

According to our measurements, the appearance energy for the $\mathrm{CH}_{4} \mathrm{~N}^{+}$fragment production from the methionine molecule is $11.0 \pm 0.1 \mathrm{eV}$. Taking into account the energy released during the $\mathrm{H}$ atom attachment, the calculated appearance energies for this fragment according to pathways (5) and (6) are $12.13 \mathrm{eV}$ and $9.30 \mathrm{eV}$, respectively.

Another assignment of the peak with the $m=$ 30 a.m.u. mass is $\mathrm{CH}_{2} \mathrm{O}^{+}$. But its appearance from the amino acid molecules requires essential energy, and, therefore, formation of this ion is less probable than that of the $\mathrm{CH}_{4} \mathrm{~N}^{+}$ion.

The fragment with the $m=29$ a.m.u. mass may be assigned to the $\mathrm{COH}^{+}$or $\mathrm{CH}_{3} \mathrm{~N}^{+}$ion. According to the results of theoretical investigation, one may state that in all cases the $\mathrm{COH}$ fragment formation is a complicated process because the probability of the simultaneous $\mathrm{C}-\mathrm{O}$ and $\mathrm{C}-\mathrm{C}$ bonds rupture is very low. In addition, the stability of the $\mathrm{CHO}^{+}$fragment is lower than that of the $\mathrm{CH}_{3} \mathrm{~N}^{+}$ion and this fact explains why the peak with $m=$ 29 a.m.u. is not assigned as $\mathrm{CHO}^{+}$. Hence, the fragment with $m=29$ a.m.u. is preferably the $\mathrm{CH}_{3} \mathrm{~N}^{+}$cation.

For the glycine molecule, the $\mathrm{CH}_{3} \mathrm{~N}^{+}$fragment formation occurs with the minimal energy consumption in case of the process $\mathrm{C}_{2} \mathrm{H}_{5} \mathrm{NO}_{2}+\mathrm{e} \rightarrow\left(\mathrm{CHO}_{2}+\mathrm{H}\right)^{0}+$ $\mathrm{CH}_{3} \mathrm{~N}^{+}+2 \mathrm{e}$. Our analysis of the charge distribution for the $\left(\mathrm{CHO}_{2}+\mathrm{H}\right)$ fragment group shows that the minimal energy corresponds to the $\mathrm{CH}_{2} \mathrm{O}_{2}$ compound production. Thus, the break of the $\mathrm{C}-\mathrm{C}$ bond accompanied by the $\mathrm{H}$ atom migration from the amino group to oxygen of 
the carbonyl group is the most probable channel of the $\mathrm{CH}_{3} \mathrm{~N}^{+}$fragment formation for glycine.

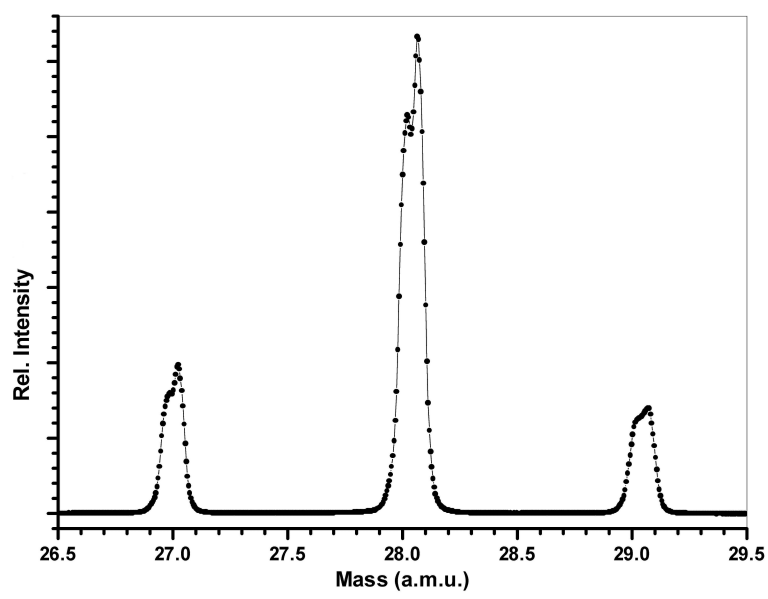

Fig. 4. The area of the DL $\alpha$-alanine mass spectrum in the 26.5-29.5 a.m.u. mass region.

In the case of the alanine molecule, we have found an interesting phenomenon not revealed in the mass spectra of other amino acids under study. A double-headed peaks of the fragments with the $m=27-29$ a.m.u. masses are due to the two constituent parts of each peak (see Fig. 4).

A double-headed peak with the $m=29$ a.m.u. mass is due to the two components and consists of the $\mathrm{CHO}^{+}$ and $\mathrm{NH}_{2} \mathrm{CH}^{+}$ions with some preference being given to the $\mathrm{CHO}^{+}$ion. The isobaric fragments with the $m=29$ a.m.u. mass could be formed according to the following pathways:

$$
\mathrm{C}_{3} \mathrm{H}_{7} \mathrm{NO}_{2}+\mathrm{e} \rightarrow\left\{\begin{array}{l}
\mathrm{CHO}^{+}+\mathrm{C}_{2} \mathrm{H}_{6} \mathrm{NO}+2 \mathrm{e}, \\
\mathrm{CH}_{3} \mathrm{~N}^{+}+\mathrm{C}_{2} \mathrm{H}_{4} \mathrm{O}_{2}^{-}+\mathrm{e}, \\
\mathrm{CH}_{3} \mathrm{~N}^{+}+\mathrm{C}_{2} \mathrm{H}_{4} \mathrm{O}_{2}+2 \mathrm{e} .
\end{array}\right.
$$

It should be noted that deuteration of the $\alpha$-alanine molecule does not assist in choosing between these two possible assignments [16] and our results show that both ions are formed in the collision event.

For the methionine molecule this fragment, as mentioned above, could be formed according to pathways (5)-(8) in the case when it is not joined with the $\mathrm{H}$ atom. According to our calculations, the lowest appearance energy of $\mathrm{CH}_{3} \mathrm{~N}^{+}$is required when the methionine molecule is divided into the ion pair according to the following pathway (when the ion geometry is the same as in the core molecule, i.e. the equilibrium point of ion is reached very slowly):

$$
\begin{aligned}
& \mathrm{C}_{5} \mathrm{H}_{11} \mathrm{NO}_{2} \mathrm{~S}+\mathrm{e} \rightarrow \\
& \quad \mathrm{CH}_{3} \mathrm{~N}^{+}+\left(\mathrm{COOH}+\mathrm{C}_{3} \mathrm{H}_{7} \mathrm{~S}\right)^{-}+\mathrm{e} .
\end{aligned}
$$

It should be noted that the calculated appearance energy for the $\mathrm{CH}_{3} \mathrm{~N}^{+}$fragment is at least $3.48 \mathrm{eV}$ higher than that for the $\left(\mathrm{CH}_{3} \mathrm{~N}+\mathrm{H}\right)^{+}$fragment. Based on these results, we can predict that the electron-impact fragmentation of methionine producing the $\left(\mathrm{CH}_{3} \mathrm{~N}+\mathrm{H}\right)^{+}$fragment is more probable than that for the $\mathrm{CH}_{3} \mathrm{~N}^{+}$fragment.

The $m=28$ a.m.u. ion may have the following gross formulae: $\mathrm{CH}_{2} \mathrm{~N}, \mathrm{C}_{2} \mathrm{H}_{4}$ and $\mathrm{CO}$. The comparison of the stability of the $\mathrm{C}_{2} \mathrm{H}_{4}^{+}, \mathrm{CH}_{2} \mathrm{~N}^{+}$and $\mathrm{CO}^{+}$ions allows us to conclude that $\mathrm{C}_{2} \mathrm{H}_{4}^{+}$is more stable than both $\mathrm{CO}^{+}$ and $\mathrm{CH}_{2} \mathrm{~N}^{+}$. In case of alanine and methionine [17], we found that formation of the $\mathrm{CO}^{+}$ion is energetically less probable than that of the $\mathrm{C}_{2} \mathrm{H}_{4}^{+}$and $\mathrm{CH}_{2} \mathrm{~N}^{+}$ions.

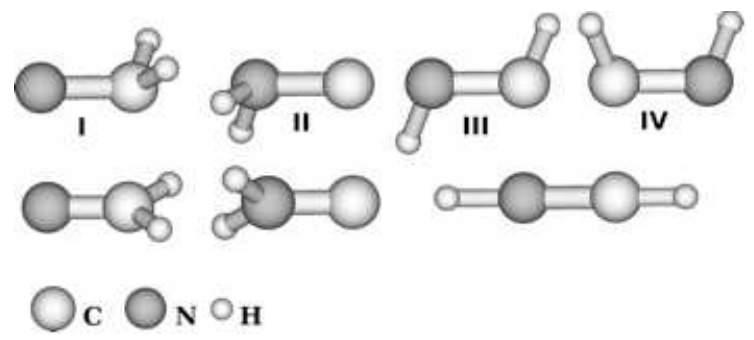

Fig. 5. The $\mathrm{CH}_{2} \mathrm{~N}^{+}$cation isomers before (top) and after (bottom) the geometry optimization.

The structure of the $\mathrm{CH}_{2} \mathrm{~N}^{+}$ion depends on the parent or intermediate ion bonds being broken. Four possible relevant isomers are shown in Fig. 5. It is important that in cases when different bonds of the $\mathrm{CH}_{4} \mathrm{~N}^{+}$or $\mathrm{CH}_{3} \mathrm{~N}^{+}$cation are broken the fragments become planar after the geometry optimization. Calculations [16] have shown that the HCNH structure is the most stable of those presented in Fig. 5. According to our calculations, when the geometry optimization is performed with the B3LYP cc-pVTZ approach application, the trans- and cis-isomers (III and IV in Fig. 5) transit to the most stable structure with the linear configuration (the point group $C_{s}$ ). Note that the $\mathrm{C}$ and $\mathrm{N}$ atoms in this case undergo the $s p$-hybridization.

In the case of the glycine molecule the fragment with $m=28$ a.m.u. is the positively charged $\mathrm{CH}_{2} \mathrm{~N}^{+}$ion because the experiment for the deuterated $d 5$ - and $d 3$ glycine [16] has unambiguously shown that this peak belongs to the $\mathrm{CH}_{2} \mathrm{~N}^{+}\left(\mathrm{CD}_{2} \mathrm{~N}^{+}\right)$ion.

In the alanine molecule mass spectrum, the ion with the $m=28$ a.m.u. mass is the second intensity-related peak and may have gross formulae: $\mathrm{CH}_{2} \mathrm{~N}, \mathrm{C}_{2} \mathrm{H}_{4}$ and $\mathrm{CO}$. Jochims et al. [16], Ipolyi et al. [18] and Bari et al. [19] assigned it to the $\mathrm{HCNH}^{+}$ion exceptionally, but Lago et al. [20] identified this peak as consisting of the $\mathrm{HCNH}^{+}$ and $\mathrm{CO}^{+}$ions. In our spectrum, only two distinct peaks arise in the vicinity of the 28 a.m.u. mass (see Fig. 4), so at least two ions may contribute to this peak.

According to the qualitative mass-spectrometry theory, where the direction of fragmentation of the molecular ion is defined by the stability of the fragments produced, formation of the $\mathrm{CH}_{2} \mathrm{~N}^{+}$ion in the case of alanine molecule seems to be most probable according to the following pathways:

$$
\begin{gathered}
\mathrm{C}_{3} \mathrm{H}_{7} \mathrm{NO}_{2}^{+} \rightarrow \mathrm{CH}_{2} \mathrm{~N}^{+}+\left(\mathrm{CH}_{3}+\mathrm{CO}_{2}+2 \mathrm{H}\right)^{\bullet} \rightarrow \\
\mathrm{CH}_{2} \mathrm{~N}^{+}+\left(\mathrm{CH}_{3}^{\bullet}+\mathrm{CO}_{2}+\mathrm{H}_{2}\right)
\end{gathered}
$$


and

$$
\mathrm{C}_{3} \mathrm{H}_{7} \mathrm{NO}_{2}^{+} \rightarrow \mathrm{CH}_{2} \mathrm{~N}^{+}+\left(\mathrm{CH}_{3}+\mathrm{CO}+(\mathrm{OH}+\mathrm{H})\right)^{\bullet}
$$

Thus, the fragments that might be produced are the stable molecules and the radical. But our calculations of the appearance energy for the $\mathrm{CH}_{2} \mathrm{~N}^{+}$fragment according to the pathways $(13,14)$ show that the system does not reach its equilibrium state, i.e. these processes are not completely realized during the alanine molecule electronimpact dissociation. So, we have calculated the $\mathrm{CH}_{2} \mathrm{~N}^{+}$ ion production from the alanine molecule with different bonds being ruptured. If the equilibrium geometry structure of the alanine molecule fragments is taken into account, the smallest appearance energies were obtained by us when the $\mathrm{CH}_{2} \mathrm{~N}^{+}$ion was formed according to the following general pathways:

$$
\begin{aligned}
& \mathrm{C}_{3} \mathrm{H}_{7} \mathrm{NO}_{2}+\mathrm{e} \rightarrow \\
& \left\{\begin{array}{l}
\mathrm{CH}_{2} \mathrm{~N}^{+}+\left(\mathrm{COOH}+\mathrm{H}+\mathrm{CH}_{3}\right)^{-}+\mathrm{e}, \\
\mathrm{CH}_{2} \mathrm{~N}^{+}+\left(\mathrm{COOH}+\mathrm{H}+\mathrm{CH}_{3}\right)+2 \mathrm{e} \\
\mathrm{CH}_{2} \mathrm{~N}^{+}+\left(\mathrm{COOH}+\mathrm{H}+\mathrm{CH}_{3}\right)^{+}+3 \mathrm{e} .
\end{array}\right.
\end{aligned}
$$

The calculated energies required to produce the above fragments are listed in Table III.

TABLE III

The calculated appearance energies (in eV) for the $\mathrm{CH}_{2} \mathrm{~N}$ and $\left(\mathrm{COOH}+\mathrm{H}+\mathrm{CH}_{3}\right)$ fragments formed from the alanine molecule.

\begin{tabular}{c|c|c}
\hline \hline $\begin{array}{c}\mathrm{C}-\mathrm{NH}_{2} \\
\text { fragment charge }\end{array}$ & $\begin{array}{c}\mathrm{COOH}+\mathrm{H}+\mathrm{CH}_{3} \\
\text { fragment charge }\end{array}$ & $\begin{array}{c}\text { Appearance } \\
\text { energy }\end{array}$ \\
\hline 1 & -1 & 9.98 \\
1 & 0 & 12.41 \\
1 & 1 & 19.51
\end{tabular}

The experimental appearance energies for the $\mathrm{CH}_{2} \mathrm{~N}^{+}$ fragment are most adequately described by pathways (15) and (16).

Two ways of formation of the $\mathrm{CH}_{2} \mathrm{~N}$ fragment from the methionine molecule were investigated because this fragment could be produced when two $\mathrm{C}-\mathrm{C}$ and $\mathrm{C}-\mathrm{H}$ or $\mathrm{N}-\mathrm{H}$ bonds of the initial molecule are ruptured. It implies that the $\mathrm{CH}_{2} \mathrm{~N}$ fragment could have structures just like those presented in Fig. 5. The analysis of the appearance energies for the $\mathrm{CH}_{2} \mathrm{~N}^{+}$fragment produced from the neutral and ionized molecule shows that the calculated appearance energy $11.83 \mathrm{eV}$ according to the pathway

$$
\mathrm{C}_{5} \mathrm{H}_{11} \mathrm{NO}_{2} \mathrm{~S}^{+} \rightarrow \mathrm{CH}_{2} \mathrm{~N}^{+}+\left(\mathrm{CHO}_{2}+\mathrm{H}+\mathrm{C}_{3} \mathrm{H}_{7} \mathrm{~S}\right)
$$

coincides with the measured value $11.4 \pm 0.1 \mathrm{eV}$.

The fragment with $m=28$ a.m.u. in the cases of alanine and methionine molecules can be not the positively charged $\mathrm{CH}_{2} \mathrm{~N}^{+}$ion only, but the $\mathrm{C}_{2} \mathrm{H}_{4}^{+}$ion as well. The stable structure for this $\mathrm{C}_{2} \mathrm{H}_{4}^{+}$fragment corresponds to that of the ethylene molecule, and its formation is accompanied by the carbon atom hybridization change from $s p^{3}$ to $s p^{2}$. However, based on our results of studies, it is not possible to find formation of what fragments, i.e. $\mathrm{CH}_{2} \mathrm{~N}^{+}$or $\mathrm{C}_{2} \mathrm{H}_{4}^{+}$, is more probable.

As for the calculated appearance energies for the $\mathrm{CH}_{2} \mathrm{~N}^{+}$and $\mathrm{C}_{2} \mathrm{H}_{4}^{+}$fragments for alanine (see Tables III, IV), it should be noted that they are a bit different.

\section{TABLE IV}

Calculated appearance energies (in $\mathrm{eV}$ ) for the $\mathrm{C}_{2} \mathrm{H}_{4}$ and $\left(\mathrm{NH}_{2}+\mathrm{COOH}\right)$ fragments formed from the alanine molecule.

\begin{tabular}{c|c|c}
\hline \hline $\begin{array}{c}\mathrm{C}_{2} \mathrm{H}_{4}(m=28 \text { a.m.u. }) \\
\text { fragment charge }\end{array}$ & $\begin{array}{c}\mathrm{NH}_{2}+\mathrm{COOH} \\
\text { fragment charge }\end{array}$ & $\begin{array}{c}\text { Appearance } \\
\text { energy }\end{array}$ \\
\hline 1 & -1 & 13.44 \\
1 & 0 & 11.80
\end{tabular}

Thus, in case of the $\mathrm{C}_{2} \mathrm{H}_{4}^{+}$ion, the appearance energy is smaller by more than $4 \mathrm{eV}$ if the alanine molecule geometry was not changed. It implies that when the fragment energy is minimal and the level of its excitation is below the energy barrier for dissociation, the appearance of the $\mathrm{C}_{2} \mathrm{H}_{4}^{+}$ion is more probable. When the positively charged ion and the neutral fragment are formed, the appearance energy values become very close, so both the $\mathrm{C}_{2} \mathrm{H}_{4}^{+}$and $\mathrm{CH}_{2} \mathrm{~N}^{+}$ions might arise. Thus, we may conclude that two isobaric ions peaks with the $m=28$ a.m.u. mass in the experimental spectra belong to the $\mathrm{C}_{2} \mathrm{H}_{4}^{+}$and $\mathrm{CH}_{2} \mathrm{~N}^{+}$ions and the channel of the $\mathrm{C}_{2} \mathrm{H}_{4}^{+}$ion formation is more efficient at the $70 \mathrm{eV}$ collision energy than that of the $\mathrm{CH}_{2} \mathrm{~N}^{+}$ion.

The $\mathrm{C}_{2} \mathrm{H}_{4}^{+}$fragment of the methionine molecule could be formed as follows:

$$
\begin{aligned}
& \mathrm{C}_{5} \mathrm{H}_{11} \mathrm{NO}_{2} \mathrm{~S}+\mathrm{e} \rightarrow \\
& \quad \mathrm{C}_{2} \mathrm{H}_{4}^{+}+\left(\mathrm{C}_{2} \mathrm{H}_{4} \mathrm{O}_{2} \mathrm{~N}+\mathrm{CH}_{3} \mathrm{~S}\right)^{-/ 0 /+}+n \mathrm{e} .
\end{aligned}
$$

Here $n=1,2,3$.

\section{TABLE V}

Calculated appearance energies (in eV) for the $\mathrm{C}_{2} \mathrm{H}_{4}$ and $\left(\mathrm{C}_{2} \mathrm{H}_{4} \mathrm{O}_{2} \mathrm{~N}+\mathrm{CH}_{3} \mathrm{~S}\right)$ fragments of the methionine molecule.

\begin{tabular}{c|c|c}
\hline \hline $\begin{array}{c}\mathrm{C}_{2} \mathrm{H}_{4}(m=28 \text { a.m.u. }) \\
\text { fragment charge }\end{array}$ & $\begin{array}{c}\left(\mathrm{C}_{2} \mathrm{H}_{4} \mathrm{O}_{2} \mathrm{~N}+\mathrm{CH}_{3} \mathrm{~S}\right) \\
\text { fragment charge }\end{array}$ & $\begin{array}{c}\text { Appearance } \\
\text { energy }\end{array}$ \\
\hline 1 & -1 & 9.52 \\
1 & 0 & 10.98 \\
1 & 1 & 22.2
\end{tabular}

In this case much attention should be paid to the energy released due to a rapid change in the geometrical structure of the $\mathrm{C}_{2} \mathrm{H}_{4}$ fragment. This energy is equal to $2.44 \mathrm{eV}$. Hence, if the released energy is taken into account, the $\mathrm{C}_{2} \mathrm{H}_{4}^{+}$ion is produced, most probably, according to a pathway with ion pair production (see Table $\mathrm{V}$ ).

The positively charged $\mathrm{CH}_{3} \mathrm{~N}^{+}$and $\mathrm{CH}_{2} \mathrm{~N}^{+}$ions could result from the secondary dissociation of the $\mathrm{CH}_{4} \mathrm{~N}^{+}$ion, 
while the $\mathrm{CH}_{2} \mathrm{~N}^{+}$ion could also appear due to deprotonation of the $\mathrm{CH}_{3} \mathrm{~N}^{+}$ion. The above secondary dissociation is more possible in case when the energy transferred to the initial molecule increases. Our experimental mass spectra of the glycine and methionine molecules reveal a diffuse peak at the mass of about $m^{*} \approx 26.1$ a.m.u. [7, 9] that corresponds to the $30 \rightarrow 28$ transition with the detachment of a neutral fragment with $m=2$ a.m.u., i.e. the secondary fragmentation of the $\mathrm{CH}_{4} \mathrm{~N}^{+}$ion occurs. Due to this dehydration, when the stable hydrogen molecule is formed as the dissociation product, the fragment with the mass of $m=29$ a.m.u. seems less probable as well. However, this dissociation channel was not observed by us for $\alpha$-alanine. Thus, the dehydration process according to the pathway $\mathrm{CH}_{4} \mathrm{~N}^{+} \rightarrow \mathrm{H}_{2}^{0}+\mathrm{CH}_{2} \mathrm{~N}^{+}$is not realized in the electron-impact-induced alanine molecule fragmentation. The probable cause of this phenomenon is the marginal pathway of the $\mathrm{CH}_{4} \mathrm{~N}^{+}$formation in the electron impact dissociation of the alanine molecule as compared with glycine and methionine.

\subsubsection{Fragments with the $m=42$, 44 and 57 a.m.u. masses}

In the mass range 40-44 a.m.u., a perceptible peak at $m=42$ a.m.u. was observed experimentally in the methionine and alanine mass spectra. This peak may be attributed to the $\mathrm{C}_{2} \mathrm{H}_{4} \mathrm{~N}^{+}$ion. In case of glycine, to produce the $\mathrm{C}_{2} \mathrm{H}_{4} \mathrm{~N}^{+}$fragment $(m=42$ a.m.u.) the $\mathrm{C}=\mathrm{O}$ and the $\mathrm{C}-\mathrm{OH}$ bonds must be broken. It is known that the average bond energy for the $\mathrm{C}=\mathrm{O}$ and the $\mathrm{C}-\mathrm{O}$ bonds is $\approx 8.28 \mathrm{eV}$ and $\approx 3.7 \mathrm{eV}$, respectively, while for $\mathrm{C}-\mathrm{C}$ it is about $3.61 \mathrm{eV}$ [21]. The simplest observation allows one to predict that reaction producing the $\mathrm{C}_{2} \mathrm{H}_{4} \mathrm{~N}^{+}$ fragment in the case of glycine is energy consuming and, thus, should be deemed not possible or having very low probability to occur.

\section{TABLE VI}

Total (internal) energies of the $\mathrm{C}_{2} \mathrm{H}_{4} \mathrm{~N}^{+}$fragment with different geometrical structure.

\begin{tabular}{c|c|c}
\hline \hline Fragment structure & $\begin{array}{c}\text { Total energy } \\
\text { [a.u.] }\end{array}$ & $\begin{array}{c}\text { Total energy } \\
\text { difference }[\mathrm{eV}]\end{array}$ \\
\hline $\mathrm{NH}_{2}-\mathrm{CH}_{2}-\mathrm{C}$ & -132.88 & 2.84 \\
$\mathrm{CH}_{3}-\mathrm{CH}=\mathrm{N}$ & -132.97 & 0.54 \\
$\mathrm{CH}_{3}-\mathrm{C} \equiv \mathrm{NH}$ & -132.99 & 0 \\
$\mathrm{CH}_{2}=\mathrm{CH}-\mathrm{NH}$ & -132.91 & 2.15 \\
$\mathrm{CH}_{2}=\mathrm{C}-\mathrm{NH}_{2}$ & -132.97 & 0.44
\end{tabular}

For the alanine molecule, the $\mathrm{C}_{2} \mathrm{H}_{4} \mathrm{~N}^{+}$ion formation is energetically more probable, because in this case the weaker $\mathrm{C}-\mathrm{C}$ and two $\mathrm{N}-\mathrm{H}$ bonds could be broken. It implies that the mechanism of the $\mathrm{C}_{2} \mathrm{H}_{4} \mathrm{~N}^{+}$ion production includes the detachment of a carboxyl group from the initial molecule being accompanied by the molecular hydrogen formation as well as by the $\mathrm{H}$ atoms migration. Jochims et al. [16] and Ipolyi et al. [18] identified this fragment as $\mathrm{NH}_{2} \mathrm{CH}_{2}=\mathrm{C}^{\cdot+}$ and $\mathrm{CH}_{3} \mathrm{C} \equiv \mathrm{NH}^{+}$, respectively. On the other hand, we suggest the another struc- ture for this fragment, not mentioned among the possible structures calculated for this stoichiometry, presented in Table VI. To indicate the stabilities of the structures under study the energy difference is presented as well when the lowest energy is assumed to be zero. A comparison of the values of the binding energy per atom indicates that the $\mathrm{CH}_{3} \mathrm{CNH}^{+}$fragment is the most stable one, but our calculations show that the $\mathrm{C}_{2} \mathrm{H}_{4} \mathrm{~N}^{+}$ion formed in the case of the alanine and methionine molecules dissociation has another structure.

The appearance energies for the $\mathrm{C}_{2} \mathrm{H}_{4} \mathrm{~N}^{+}$ions calculated in our recent paper [9] according to the pathway $\mathrm{C}_{3} \mathrm{H}_{7} \mathrm{NO}_{2}^{+} \rightarrow \mathrm{CH}_{3} \mathrm{CNH}^{+}+\left(\mathrm{H}_{2}+\mathrm{CHO}_{2}\right)^{-}$are closer to the experimental value than the $a b$ initio result $(10.87 \mathrm{eV})$ presented in [18], where it was stated that the $\mathrm{CH}_{3} \mathrm{CNH}^{+}$ion is formed via the following reaction process: $\mathrm{C}_{3} \mathrm{H}_{7} \mathrm{NO}_{2}^{+} \rightarrow \mathrm{CH}_{3} \mathrm{CNH}^{+}+\mathrm{HCO}^{-}+\mathrm{H}_{2} \mathrm{O}$. Note that in both pathways the $\mathrm{C}_{2} \mathrm{H}_{4} \mathrm{~N}^{+}$ion appears in a case of an ion pair formation. Thus, the mechanism of the $\mathrm{C}_{2} \mathrm{H}_{4} \mathrm{~N}^{+}$ion production includes the detachment of a carboxyl group from the initial molecule accompanied by the molecular hydrogen formation rather than the disintegration process of the $\mathrm{COH}$ group and the water molecule elimination as suggested in [18].
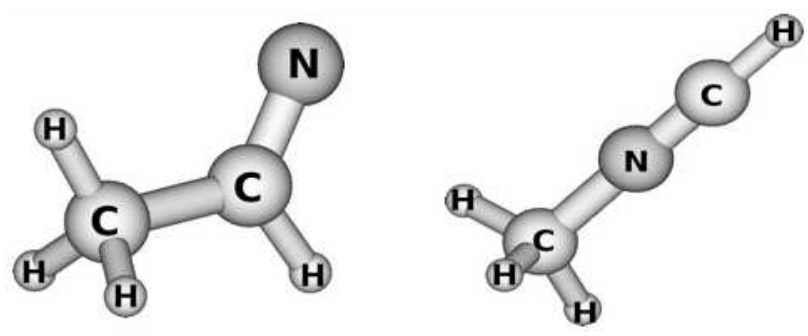

Fig. 6. Views of the $\mathrm{CH}_{3} \mathrm{CHN}^{+}$fragment when alanine is ruptured (left) and at the equilibrium point (right).

It is interesting to note that optimization results indicate changeability of the initial $\mathrm{CH}_{3} \mathrm{CHN}^{+}$ion geometrical structure. The $\mathrm{CH}_{3} \mathrm{CHN}^{+}$fragment transforms to the $\mathrm{CH}_{3} \mathrm{NCH}^{+}$one at its equilibrium point. We started our optimization from the $\mathrm{CH}_{3} \mathrm{CNH}^{+}$structure and finally obtained the $\mathrm{CH}_{3}-\mathrm{N}=\mathrm{CH}^{+}$structure. The geometrical structures of the $\mathrm{C}_{2} \mathrm{H}_{4} \mathrm{~N}^{+}$ion both before and after optimization are shown in Fig. 6.

The mechanism of the structural change during formation of the above ion could take place via the intermediate cyclic structure of the dehydrated ethylene imine according the pathway given below

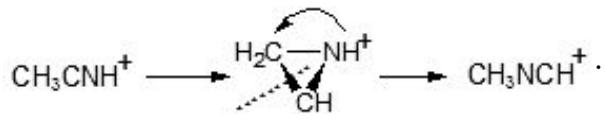

This intermediate structure can be obtained when analyzing the optimization process. The bond order analysis indicates that in the $\mathrm{C}_{2} \mathrm{H}_{4} \mathrm{~N}^{+}$positive ion structure the double bonds are formed between both the $\mathrm{N}$ and $\mathrm{C}$ atoms, while the bond order between the $\mathrm{C}-\mathrm{C}$ atoms 
is 0.846 . Thus, this bond is the weakest one in the intermediate cyclic structure, and the above bond rupture is possible. In the obtained structure, the $\mathrm{C}$ atom undergoes, obviously, the $s p$-hybridization.

In case of the methionine molecule, $\mathrm{C}_{2} \mathrm{H}_{4} \mathrm{~N}^{+}$fragment could be formed via the following pathway:

$$
\begin{aligned}
& \mathrm{C}_{5} \mathrm{H}_{11} \mathrm{NO}_{2} \mathrm{~S}+\mathrm{e} \rightarrow \\
& \quad \mathrm{C}_{2} \mathrm{H}_{4} \mathrm{~N}^{+}+\left(\mathrm{C}_{2} \mathrm{H}_{5} \mathrm{~S}+\mathrm{H}+\mathrm{CHO}_{2}\right)^{-}+\mathrm{e},
\end{aligned}
$$

where the $\mathrm{C}_{2} \mathrm{H}_{4} \mathrm{~N}^{+}$ion has the following structure: $\mathrm{CH}_{2}=\mathrm{CH}-\mathrm{NH}$. Formation of the initial structure was predicted based on studying the bond order. On the other hand, we have checked the channel of formation of the fragment with the $\mathrm{CH}_{2}=\mathrm{C}-\mathrm{NH}_{2}$ structure that is more stable than $\mathrm{CH}_{2}=\mathrm{CH}-\mathrm{NH}$, but less stable than $\mathrm{CH}_{3}-$ $\mathrm{C} \equiv \mathrm{NH}$. Notably, the most stable $\mathrm{CH}_{3} \mathrm{C} \equiv \mathrm{NH}$ fragment cannot be formed in the case of methionine. It should be mentioned that the measured appearance energy for the $\mathrm{C}_{2} \mathrm{H}_{4} \mathrm{~N}^{+}$fragment is $12.9 \mathrm{eV}$, while calculated one is $9.37 \mathrm{eV}$ or $6.95 \mathrm{eV}$. Taking into account that the fragments are not the most stable ones (see Table VI), one may predict the $\mathrm{H}$ atom migration that requires the $2.15 \mathrm{eV}$ or $0.44 \mathrm{eV}$ energy.

Hence, the $\mathrm{C}_{2} \mathrm{H}_{4} \mathrm{~N}^{+}$ion in the case of the alanine and methionine molecules has a different structure.

The peak at $m=44$ a.m.u. observed in the experimental mass spectra can be attributed to the $\mathrm{CO}_{2}^{+}$for all three molecules under study, $\mathrm{C}_{2} \mathrm{H}_{6} \mathrm{~N}^{+}$in case of alanine and methionine but in the latter case it may also be $\mathrm{CS}^{+}$.

In the glycine mass spectrum, the peak at $m=$ 44 a.m.u. can be attributed to the $\mathrm{CO}_{2}^{+}$ion only and the relative intensity of this peak is $5.8 \%$ [6]. For the $\mathrm{CO}_{2}$ fragment, the relevant complementary fragment corresponds to $\mathrm{CH}_{3} \mathrm{NH}_{2}$. This pair of fragments is produced due to the hydrogen atom migration from the hydroxyl group to the carbon atom via the 4-term transient state. Two alternative decay channels are possible here differing by both the reaction rate and the final charge localization

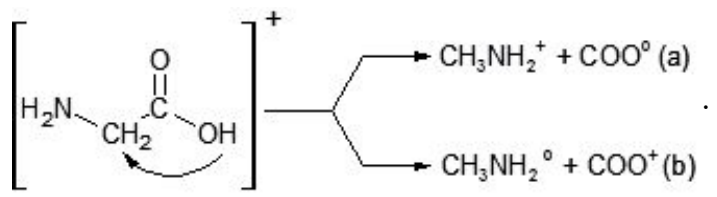

The intensities of the corresponding peaks in the massspectrum may characterize the efficiencies of the above reaction channels. According to our data, the intensity of the $m=44$ a.m.u. peak is higher than that of the $m=31$ a.m.u. peak, thus, in case of the $\mathrm{C}-$ $\mathrm{C}$ bond dissociation accompanied by the hydroxyl group $\mathrm{H}$ atom migration; the cation center is mainly displaced to the $\mathrm{CO}_{2}$ fragment and the neutral $\mathrm{CH}_{3} \mathrm{NH}_{2}$ fragment is eliminated.

We have checked the possibility of $\mathrm{CO}_{2}^{+}$formation at the dissociative ionization of the alanine and methionine molecules. The calculated results indicate that production of this ion is energetically non-favorable because its appearance energy is approximately twice larger than that for the isobaric $\mathrm{C}_{2} \mathrm{H}_{6} \mathrm{~N}^{+}$fragment. Summarizing previously mentioned, it is possible to conclude that the peak at $m=44$ a.m.u. in the experimental mass spectra of the alanine and methionine molecules could be attributed to the formation of the $\mathrm{C}_{2} \mathrm{H}_{6} \mathrm{~N}^{+}$fragment. For the alanine molecule the appearance of the $\mathrm{C}_{2} \mathrm{H}_{6} \mathrm{~N}^{+}$fragment is described above as the result of the $\mathrm{C}-\mathrm{C}_{\alpha}$ bond rupture and the carboxyl group detachment. However, we failed to find the channel of this fragment formation from the methionine molecule: the calculated appearance energy of this fragment is approximately $5 \mathrm{eV}$ less than the measured one or $4 \mathrm{eV}$ higher, when this peak is assigned as $\mathrm{CS}^{+}$.

We also predicted the formation of the $m=57$ a.m.u. fragment that can be attributed to the $\mathrm{C}_{2} \mathrm{HO}_{2}^{+}$or $\mathrm{C}_{2} \mathrm{H}_{3} \mathrm{NO}^{+}$ions, but the relevant peak with small intensity $(\approx 12 \%)$ is present in the methionine mass-spectrum only. For the glycine and alanine molecules the intensity of the peak at $m=57$ a.m.u. is small $(\approx 0.2-0.4 \%)$ despite of the high stability of the $\mathrm{C}_{2} \mathrm{H}_{3} \mathrm{NO}^{+}$fragment and the small-scale calculated appearance energy for this fragment $(9.38 \mathrm{eV}$ and $11.23 \mathrm{eV}$ for glycine and alanine, respectively).

It is interesting, in our opinion, to note that in the glycine and methionine mass spectra (but not in the case of alanine) a weak peak located at $m=28.5$ a.m.u. is observed experimentally $[7,9]$. Obviously, this peak is assigned to the doubly charged $\mathrm{C}_{2} \mathrm{H}_{3} \mathrm{NO}^{2+}$ ion. Formation of this ion requires the water molecule elimination after the two-electron loss from the first two highest occupied molecular orbitals of the parent molecule. The calculation of the energy required to produce the doubly charged $\mathrm{C}_{2} \mathrm{H}_{3} \mathrm{NO}^{2+}$ ion from the neutral glycine molecule with multiplicity 1 shows that the hydrogen atom detachment from the carbon atom proceeds with a higher probability than that from the nitrogen atom. As for the methionine molecule, the $\mathrm{C}_{2} \mathrm{H}_{3} \mathrm{NO}^{2+}$ ion occurs after the doubly charged parent molecule ion skeleton $\mathrm{C}-\mathrm{C}$ bond dissociation accompanied by the water molecule elimination. Taking into account that the hydroxyl group and the hydrogen atom required for the water molecule formation are located in the opposite parts of a parent molecule, one may conclude that $\mathrm{H}_{2} \mathrm{O}$ is eliminated simultaneously or slightly before the skeleton bond dissociation.

\section{Conclusions}

We have studied both experimentally (applying the mass-spectrometric technique with the \pm 0.25 a.m.u. mass resolution) and theoretically (using the DFT-based theoretical approach) the mass spectra of the amino acid molecules (glycine, alanine, methionine) and have identified the main components having the same chemical composition/masses. Their absolute appearance potentials have been determined. The analysis of the obtained results using the newly developed DFT approach has allowed the principal mechanisms of the initial amino acid 
molecules dissociation/fragmentation to be established with the allowance made for the charges of the ionic fragments produced.

We have shown that the different substituents influence the amino acid molecules fragmentation, i.e. only few amino acids produce the same fragments despite their core part similarities.

The hydrogen atom substitution in glycine by the methyl group in alanine does not influence the main fragmentation channel when the molecules undergo the lowenergy electron impact: the $\mathrm{C}-\mathrm{C}_{\alpha}$ bond rupture and the carboxyl group detachment, but the presence of the sulfur atom due to the influence on the HOMO character leads to the dissociation occurred via the $\mathrm{C}_{\beta}-\mathrm{C}_{\gamma}$ bond rupture.

Our calculations have shown that the side chain of amino acid influences both the atomic composition of fragments with the same mass and their structure. For example, the $\mathrm{C}_{2} \mathrm{H}_{4} \mathrm{~N}^{+}$ion in the case of the alanine and methionine molecules has different structure.

One may conclude, based on our data of both experimental and theoretical investigations, that for all molecules studied the positively charged $\mathrm{CH}_{3} \mathrm{~N}^{+}$and $\mathrm{CH}_{2} \mathrm{~N}^{+}$ions could result from the secondary dissociation due to the deprotonation of the $\mathrm{CH}_{4} \mathrm{~N}^{+}$ions, while the $\mathrm{CH}_{2} \mathrm{~N}^{+}$ion also appear due to the deprotonation of the $\mathrm{CH}_{3} \mathrm{~N}^{+}$ion. The observations of that kind could be of great importance for studying the malignant transformations in living cells under the influence of ionizing radiation and also provide useful radiation therapy effect on tumors in human beings.

\section{Acknowledgments}

The authors would like to thank Prof. M. Cegla (Jagiellonian University, Kraków, Poland) and our colleague V. Patasiene (Vilnius University, Vilnius, Lithuania) for their technical support and assistance in carrying out this study. Special thanks go to the InSpire and NGI.LT projects for the resources and support of theoretical calculations provided as well as to the COST MP0802 activity.

\section{References}

[1] U. Meierhenrich, Amino Acids and the Asymmetry of Life, Springer-Verlag, Berlin 2008.

[2] L. Delaye, A. Lazcano, Phys. Life Rev. 2, 47 (2005).
[3] S. Cristoni, L.R. Bernardi, Mass Spectrosc. Rev. 22, 369 (2003).

[4] B.D. Michael, P.A. O'Neill, Science 287, 1603 (2000).

[5] A. Brack, The Molecular Origins of Life, Cambridge University Press, Cambridge 1998, p. 417.

[6] National Institute of Standards, Standard Reference Database: Chemistry Webbook, http://webbook. nist.gov.

[7] J. Tamuliene, L.G. Romanova, V.S. Vukstich, A.V. Snegursky, Chem. Phys. 404, 36 (2012).

[8] J. Tamuliene, L.G. Romanova, V.S. Vukstich, A.V. Snegursky, Lith. J. Phys. 53, 195 (2013).

[9] J. Tamuliene, L.G. Romanova, V.S. Vukstich, A.V. Snegursky, Chem. Phys. 404, 74 (2012).

[10] V.S. Vukstich, A.I. Imre, A.V. Snegursky, Instr. Exp. Tech. 54, 207 (2011).

[11] G. Hanel, B. Gstir, T. Fiegele, F. Hagelberg, K. Becker, P. Scheier, A. Snegursky, T. Märk, J. Chem. Phys. 116, 2456 (2002).

[12] A.D. Becke, J. Chem. Phys. 98, 5648 (1993).

[13] R.A. Kendall, T.H. Dunning Jr., R.J.J. Harrison, J. Chem. Phys. 96, 6796 (1992).

[14] G.A. Junk, H.J. Svec, J. Am. Chem. Soc. 85, 839 (1963).

[15] V.S. Vukstich, A.I. Imre, L.G. Romanova, A.V. Snegursky, J. Phys. B 43, 185208 (2010).

[16] H.-W. Jochims, M. Schwell, J.-L. Chotin, M. Clembino, F. Dulieu, H. Baumgärtel, S. Leach, Chem. Phys. 298, 279 (2004).

[17] J. Tamuliene, L.G. Romanova, V.S. Vukstich, A.V. Snegursky, Nucl. Instrum. Methods Phys. Rev. B 279, 128 (2012).

[18] P. Ipolyi, S. Cicman, V. Denifl, K. Matejčik, P. Mach, J. Urban, P. Scheier, T.D. Märk, Š. Matejčik, Int. J. Mass Spectrosc. 252, 228 (2006).

[19] S. Bari, P. Sobocinski, J. Postma, F. Alvarado, R. Hoekstra, V. Bernigaud, B. Manil, J. Rangama, B. Huber, T. Schlathölter, J. Chem. Phys. 128, 074306 (2008).

[20] A.F. Lago, L.H. Coutinho, R.R.T. Marinho, A. Naves de Brito, G.G.B. de Souza, Chem. Phys. 307, 9 (2004).

[21] Mr. Kent's Chemistry Page: Bond Enthalpy, www . kentchemistry. com. 